This item was submitted to Loughborough's Research Repository by the author.

Items in Figshare are protected by copyright, with all rights reserved, unless otherwise indicated.

\title{
Computational modelling and experimental validation of the thermal fusion bonding process in porous fibrous media
}

PLEASE CITE THE PUBLISHED VERSION

http://dx.doi.org/10.1177/0954408910396785

\section{PUBLISHER}

(c) Published by Sage on behalf of Professional Engineering Publishing (Institution of Mechanical Engineers)

\section{VERSION}

VoR (Version of Record)

\section{LICENCE}

CC BY-NC-ND 4.0

\section{REPOSITORY RECORD}

Peksen, Murat, Memis Acar, and W. Malalasekera. 2019. "Computational Modelling and Experimental Validation of the Thermal Fusion Bonding Process in Porous Fibrous Media". figshare. https://hdl.handle.net/2134/8991. 
This item was submitted to Loughborough's Institutional Repository (https://dspace.lboro.ac.uk/) by the author and is made available under the following Creative Commons Licence conditions.

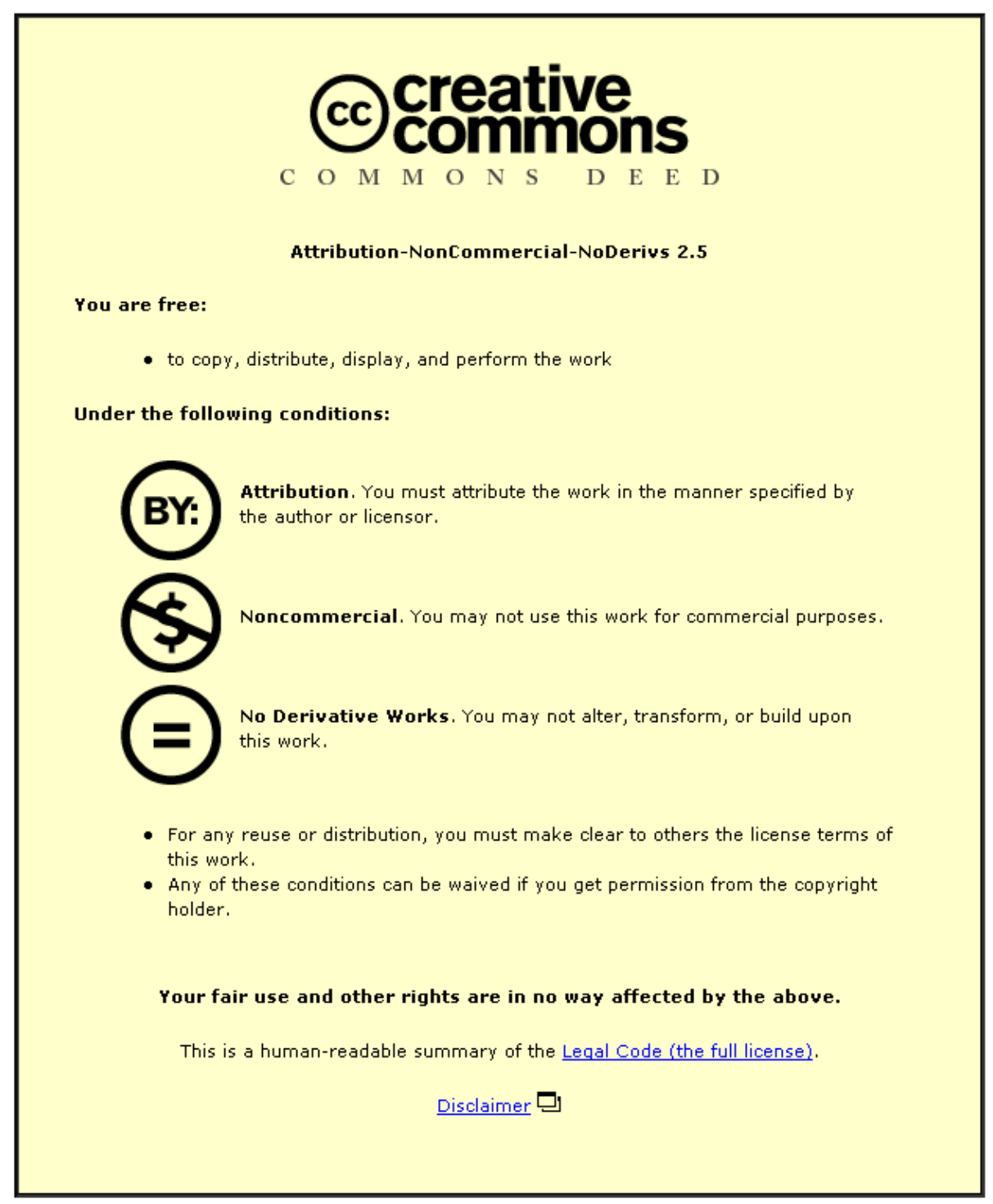

For the full text of this licence, please go to: http://creativecommons.org/licenses/by-nc-nd/2.5/ 
Citation for this paper is:

PEKSEN, M., ACAR, M. and MALALASEKERA, W., 2011. Computational modelling and experimental validation of the thermal fusion bonding process in porous fibrous media. Proceedings of the Institution of Mechanical Engineers, Part E: Journal of Process Mechanical Engineering, 225 (3), pp. 173-182.

\section{Computational Modelling and Experimental Validation of the Thermal Fusion Bonding Process in Porous Fibrous Media}

M. Peksen, M. Acar and W. Malalasekera

Wolfson School of Mechanical and Manufacturing Engineering

Loughborough University, Leicestershire, LE11 3TU, UK

Email: M.Acar@lboro.ac.uk,

Phone: +44 1509 227533, Fax: +44 1509227648 


\begin{abstract}
ABSTARCT
This paper presents a computational model of the thermal bonding of nonwovens using convective hot air and its experimental validation. A computational fluid dynamics (CFD) model based on the continuum modelling approach and the theory of porous media is developed to treat the flow behavior and heat transfer within the thermal bonding system. The model includes several components of a typical industrial machine including the conveyer belt, drum cover, drum, and the nonwoven web. Experimental measurements are used to supply appropriate boundary conditions for the simulations and to provide data for the validation of the numerically computed results. The model is concluded to be an accurate computational tool which could potentially replace the costly experiments and be employed in product development, process optimisation and machine design.
\end{abstract}

Keywords: nonwoven, thermal bonding, heat transfer, porous media, process modelling

\title{
NOMENCLATURE
}

$c \quad$ specific heat capacity $(\mathrm{J} / \mathrm{kg} \mathrm{K})$

$D_{p} \quad$ mean particle diameter (m)

$f \quad$ body force $(\mathrm{N})$

$h \quad$ enthalpy $(\mathrm{J} / \mathrm{kg})$

$k \quad$ permeability $\left(\mathrm{m}^{2}\right)$

$k_{\text {eff }} \quad$ effective thermal conductivity (W/mK)

$\Delta n \quad$ porous layer thickness $(\mathrm{m})$ 


$$
\begin{array}{ll}
P & \text { static pressure }(\mathrm{Pa}) \\
T & \text { temperature }(\mathrm{K}) \\
u & \text { velocity }(\mathrm{m} / \mathrm{s}) \\
\mathrm{x}, \mathrm{y}, \mathrm{z} & \text { cartesian coordinates }(\mathrm{m}) \\
M_{x}, M_{y} & \text { mesh number }(1 / \mathrm{mm}) \\
D_{x}, D_{y} & \text { wire filament diameter }(\mathrm{mm}) \\
t & \text { wire mesh thickness }(\mathrm{mm}) \\
S_{x}, S_{y} & \text { wire filament length }(\mathrm{mm}) \\
C_{f} & \text { compression factor }(-)
\end{array}
$$

\section{Greek symbols}

$$
\begin{array}{ll}
\phi & \text { porosity }(-) \\
\mu & \text { viscosity }(\mathrm{kg} / \mathrm{m} \mathrm{s}) \\
\rho & \text { density }\left(\mathrm{kg} / \mathrm{m}^{3}\right) \\
\beta & \text { inertial resistance coefficient (-) }
\end{array}
$$

\section{Abbreviations}

CFD computational fluid dynamics

PET polyester

\section{Subscripts}

$\begin{array}{ll}a & \text { air } \\ s & \text { solid } \\ \text { eff } & \text { effective }\end{array}$

\section{INTRODUCTION}

Nonwoven fabrics have been in use since 1930s [1]. Advantages of nonwovens processes and their products over knitting and weaving have attracted many industries such as aerospace, automotive, sports, geotextiles, composites, construction as well as medical and hygiene applications. Wet or dry laid or carded short fibre webs have insufficient strength as formed, and require a bonding process in order to produce a nonwoven fabric with desired properties. To achieve the intended properties, the 
bonding method used in the forming of a nonwoven fabric is the most important part of the production process. The through-air thermal bonding process is one of the modern techniques which relies upon passing heated air through an un-bonded porous nonwoven web to heat, soften, melt and thermally fuse the constituent fibres which are in contact with each other.

Usually, the thermoplastic fibres used in this process are made of sheath and core type bi-component fibres. A sudden temperature rise above the melting point of the sheath material melts the surface of the fibres to fuse them together, whilst the core of the bicomponent fibre, which is made of a material with a higher melting temperature than that of the sheath material, remains intact providing structural integrity to the bonded web. The final properties of the bonded nonwoven product depend on the fibre material properties, web properties, and the process properties such as the air temperature and flow rate. It is therefore, essential to determine the optimum airflow and heat transfer conditions for improved process efficiency and product quality.

A typical thermal bonding machine is schematically illustrated in Figure 1(a). The machine basically consists of a rigid perforated rotating drum, a wire-mesh drum cover and a wire-mesh looped conveyor belt. Drum and drum cover is enclosed by a hood with a small opening to allow the conveyor belt and the web to enter and leave the machine. Fibrous web enters the machine together with the conveyor belt, both at near ambient temperatures, and is then exposed to hot air flow, which is at or just above the melting temperature of the sheath fibre material. The nonwoven web is wrapped around the drum, sandwiched between the conveyor belt and the drum cover, first travelling through the machine's heating zone facilitating the bonding of the contacting fibres, and then it is briefly subjected to a cool air flow before leaving the machine.

Hot air first flows through wire meshed conveyer belt, then through the nonwoven web, and finally though the drum cover and the perforated drum. All these elements enter the heating zone at different but much lower temperatures than the air temperature, thus absorbing significant amount of energy from the air. In this work a computational model of the through-air thermal bonding process is developed, considering all layers of a typical through-air bonding machine, as well as the 
nonwoven web sandwiched between the belt and the drum cover, as illustrated in Figure 1(b).

Computational Fluid Dynamics (CFD) including heat transfer is used in the current modelling approach. Various parameters that characterise the thermal fusion bonding process, including the air temperature and velocity in the radial direction, as well as the thermal conductivity, air permeability, porosity and the resistance coefficients of the web, belt, drum and the drum cover are required for the CFD modelling. An experimental programme was undertaken to obtain the required data, such as the air velocity and temperature distribution of the nonwoven web needed to validate the model. The CFD simulations of the hot through-air thermal bonding process are validated using the experimental data obtained.

\section{MATHEMATICAL MODELLING}

The mathematical modelling focuses on the treatment of the continuity, momentum and energy equations applied to the porous media concept and they are solved using Computational Fluid Dynamics based finite volume discretisation technique. Following the approach in Hossain et all's work [2], a $5^{\circ}$ sector consisting of all layers of material involved in the thermal bonding process are considered where transient flow and heat transfer is considered in the model. In the present work no attempt is made to consider molten polymer phases. The complicated interfacial geometry of the porous fibrous web and air flow prohibits the solution of the microscopic conservation equations for momentum and energy. Therefore, a macroscopic formulation based on the volume averaging and assuming uniform porosity, single phase flow for air, is used in the present study. The fibres are laid by a process which is designed to give a random orientation distribution which in turn imparts an isotropic structure to the nonwoven web.

The problem considered here is a thermo-mechanical process governed by the fluid flow through and heat transfer to the fibrous web. As the hot air enters the fibrous web through the belt, heat is transferred to the web resulting in a rise in the fibre temperature and consequently bonding of the fibres in contact with each other. For the system consisting of the belt, non-woven layer, drum cover and drum, heat transfer 
and fluid flow is governed by the transport equations of continuity, momentum and energy. All four layers of the system have different porosities, and thermal and mechanical properties. Properties over a given surface element (drum, drum cover, belt and fibre web) are considered to be uniform over the surface (in the literature this is sometime referred to as isotropic properties). The drum surface is made of uniformly distributed perforated holes. The belt and the drum cover are homogeneous wire mesh structures. The web is a uniformly spread randomly distributed structure. Therefore assumption of uniform properties (for the direction of flow) is entirely justifiable.

\subsection{Continuity Equation}

$$
\frac{\partial\left(\phi \rho_{a}\right)}{\partial t}+\nabla\left(\rho_{a} \bar{u} \phi\right)=0
$$

Here $\rho_{a}$ is density of air and $\phi$ is porosity.

\subsection{Momentum Equation}

$$
\frac{\partial\left(\phi \rho_{a} \bar{u}\right)}{\partial t}+\left(\phi \rho_{a} \bar{u} \cdot \nabla\right) \bar{u}=-\phi \nabla P+\nabla \cdot(\phi \bar{\tau})+\phi B_{f}-\bar{S}_{i}
$$

In the above equation $B_{f}$ is body force and $S_{i}$ is the momentum sink term due viscous and inertial drag forces imposed by the porous media. Here, gravity is neglected therefore the term $B_{f}$ is not considered. The $S_{i}$ term is modelled as:

$$
S_{i}=\left(\frac{\mu}{k}+\frac{\beta \rho_{a}}{2}|\bar{u}|\right) \bar{u}
$$

This contributes to the pressure gradient in the porous cell, creating a pressure drop for a specified thickness of the porous layer. The first term on the right hand side of Eq. (3) describes the viscous loss term where $k$ is the air permeability, $\mu$ the dynamic viscosity, and $\vec{u}$ the velocity vector. The inverse of $k$ in this equation is called the constant viscous resistance factor. The Forchheimer regime, which describes the transient regime from laminar to low turbulence, is presented as inertial effects in the second term of the momentum source [3]. $\beta$ is the inertial resistance coefficient. 
For deriving the viscous and inertial loss coefficients, the following empirical relations, which are based on a simplified version of the Ergun equation [4], can be used for the drum component which consists of regular holes:

$$
k=\frac{D_{p}^{2}}{150} \frac{\phi^{3}}{(1-\phi)^{2}}
$$

$D_{p}$ is the mean particle diameter which can be substituted with the hydraulic diameter. The following equation defines the inertial resistance factor $\beta$ :

$$
\beta=\frac{3.5}{D_{p}} \frac{(1-\phi)}{\phi^{3}}
$$

Alternatively, coefficients $k$ and $\beta$ of the porous material can be experimentally determined by measuring the pressure drop against the flow velocity.

For a simple homogenous porous medium, the source term contribution in terms of the pressure gradient is a function of the fluid velocity in the cell and can be formulated as:

$$
\Delta P=a u+b u^{2}
$$

Hence, the coefficient $a$ is the viscous resistance coefficient describing the Darcy regime, where the inertial forces are negligible in comparison to the viscous forces. The inertia resistance coefficient $b$ describes the Forchheimer regime which is the transient regime from laminar to low turbulence, where

$$
a=\frac{\mu}{k} \Delta n
$$

and,

$$
b=\beta \frac{1}{2} \rho_{a} \Delta n
$$

where $\Delta n$ is the porous layer thickness. In the present study, experimental data are used for the nonwoven web, conveyer belt and the drum cover to obtain the relationship (6), and $k$ and $\beta$ values are calculated from equations (7) and (8).

\subsection{Energy Equation}


In a porous medium, the conduction flux uses an effective thermal conductivity and the transient term includes the thermal inertia of the solid region of the medium. The general form of the energy equation used in the modelling process is as follows:

$$
\frac{\partial}{\partial t}\left(\phi \rho_{a} E_{a}+(1-\phi) \rho_{S} E_{s}\right)+\nabla \cdot\left(\bar{u}\left(\rho_{a} E_{a}+p\right)\right)=\nabla \cdot\left[k_{e f f} \nabla T+(\overline{\bar{\tau}} \cdot \bar{u})\right]+S_{a}
$$

where $E_{a}$ is the specific fluid energy, $E_{s}$ the specific solid region energy, $k_{\text {eff }}$ the effective thermal conductivity of the porous medium, and $S_{a}$ the fluid enthalpy source term. The first two terms on the right-hand side of Equation (9) represent energy transfer due to heat conduction and viscous dissipation, respectively. $k_{\text {eff }}$ is computed as the volume average of the fluid conductivity and solid conductivity

$$
k_{\text {eff }}=\phi k_{a}+(1-\phi) k_{s}
$$

\subsection{Effective properties for porous media layers}

Properties of the porous media are calculated based on solid and fluid properties using porosity as the controlling parameter [5]. As the voids in the solid phase are filled with fluid, the combined fluid and solid properties define effective properties for the porous material.

\subsubsection{Density}

The effective density for both the meshed structures and the nonwoven layer can be calculated from:

$$
\rho_{e f f}=\phi \rho_{s}+(1-\phi) \rho_{a}
$$

\subsubsection{Specific heat}

The effective specific heat capacity of the wire meshed structure and the porous fibrous nonwoven layer can be calculated as follows using the effective density calculated in Eq. (11):

$$
C_{p_{e f f}}=\frac{\phi \rho_{s}\left(c_{p}\right)+(1-\phi) \rho_{a}\left(c_{p}\right)_{a}}{\rho_{e f f}}
$$

\subsubsection{Porosity}

For the porosity calculation different approaches are used for the wire mesh structures and the nonwoven fabric respectively. 


\section{Wire Mesh Structures}

Properties of the wire mesh structure (the belt and drum cover) are obtained by considering key geometrical features of the wire mesh. Figure 2(a) illustrates a discrete model of a wire mesh structure. A unit cell of the plane weave is shown in Figure 2(b). The serpentine wire filaments have diameter of $D_{x}$ and $D_{y}$, and corresponding mesh numbers $M_{x}$ and $M_{y}$. The wire filament pitches in the $x$ and $y$ directions are $1 / M_{x}(\mathrm{~mm})$ and $1 / M_{y}(\mathrm{~mm})$ respectively.

To mathematically model the wire mesh structures of the metal components, the mesh thickness has to be defined. In the absence of crimping, the mesh has a thickness of $t=\left(D_{x}+D_{y}\right)$ as shown in Fig. 2(c). The wire lengths $S_{x}$ and $S_{y}$ in the unit cell are proposed by Luo and Mitra [6] and Xu and Wirtz [7].

$$
\begin{aligned}
& S_{x}=\frac{1}{M_{x}}\left[1+9.6\left(\frac{D_{y} M_{x}}{4}\right)^{2}-49.2\left(\frac{D_{y} M_{x}}{4}\right)^{4}\right] \\
& S_{y}=\frac{1}{M_{y}}\left[1+9.6\left(\frac{D_{x} M_{y}}{4}\right)^{2}-49.2\left(\frac{D_{x} M_{y}}{4}\right)^{4}\right]
\end{aligned}
$$

The meshed structures used in this research are not layered laminates; therefore, the interleaving effect that is caused due to multiple stacked layers can be neglected. In this case, the thickness of the mesh is $t=C_{f}\left(D_{x}+D_{y}\right)$, where $C_{f}$ is the compression factor.

Restricting the attention to one layer of mesh, the compression factor is considered to be $C_{f}=1$. Homogeneous structures have equal wire thickness i.e. $D_{x}=D_{y}=D$ and an equal mesh number of $M_{x}=M_{y}=M . \mathrm{Xu}$ and Wirtz [7] have derived a general expression to calculate porosity with varying $D_{x}, D_{y}, M_{x}$ and $M_{y}$. For homogeneous 
structures where, $S_{x}=S_{y}$ the expression given by Xu and Wirtz [7] can be simplified to

$$
C_{f}(1-\phi)=\frac{\pi}{4} D \cdot M^{2} S_{x}
$$

where, $C_{f}(1-\phi)$ is the reduced metal fraction.

Since the woven structure is assumed to be homogeneous, the effective thermal conductivity of the wired structures can be calculated from the following equation given by $\mathrm{Xu}$ and Wirtz [8]:

$$
K_{y}=\left[\frac{80 \pi \cdot M \cdot D\left(K_{f s}-1\right)+C \cdot K_{f s}}{C}+\frac{C \cdot K_{f s}}{320 \cdot \pi \cdot M \cdot D \cdot\left(1-K_{f s}\right)+2 C}\right]
$$

where, $C=123(M . D)^{4}-384(M . D)^{2}-640$ is a recurring factor and $K_{y}$ is the dimensionless effective thermal conductivity, Xu and Wirtz [8]. The effective thermal conductivity $K_{\text {eff }}=K_{y} k_{s}$, where $k_{s}$ is the thermal conductivity of the solid material, $K_{f s}$ refers to $\frac{k_{f}}{k_{s}}$, where $k_{f}$ is the thermal conductivity of the air.

\section{Nonwoven Web}

Figure 3 shows the SEM image of a through air bonded nonwoven web. It can be seen that different sizes of pores are randomly present within the laid fibres. In addition multiple layers of interconnected pore structures are visible through the thickness. The number of these layers depends on the fabric weight per unit area.

The relationship between the air permeability and porosity enables the porosity of the porous nonwoven material to be approximated. The nonwoven web used in this process consists of randomly laid fibres and hence is considered to be homogenous with respect to permeability. For the calculations, therefore, isotropy is used with respect to the nonwoven's permeability.

The porosity of the porous nonwoven fabric, $\phi$, is calculated using the air permeability measurements from a model given by McGregor [9]:

$$
k=\frac{d_{f}^{2} \phi^{3}}{16(1-\phi)^{2} K_{0}}
$$


where $d_{f}$ is the fibre diameter and $k$ is the air permeability. The Kozany constant, $K_{0}$, in the equation is assumed to be 5.5 for textile assemblies.

\section{COMPUTATIONAL MODELLING}

\subsection{CFD Modelling}

For the CFD analyses, a detailed approximation of the thermal bonding machine geometry is required. The heating zone of the machine shown in Figure 1 corresponds to a $236^{\circ}$ segment. Here, the computational modelling approach uses a $2 \mathrm{D}$ analyses comprising typical components of the thermal bonding system adjacent to each other, namely the conveyer belt, nonwoven, drum cover and drum. The depth of each layer in the z-direction which is the width of the machine is $1 \mathrm{~m}$. This is long when it is compared to the thousand orders smaller value of the thickness of the analysed 4 layers; therefore, the temperature distribution along this axis is assumed to be uniform. The transient nature of the problem is considered in a quasi transient manner by considering a $5^{\circ}$ radial sector of the geometry subjected to heating for a period of time, corresponding to the dwell time of $236^{\circ}$ segment of the machine in the heating zone, based on the speed of the drum.

Each component of the system is modelled as a continuum treated as a separate 'porous zone'. In computations, experimentally determined directional properties in the main flow direction were used, i.e., the effect of porosity was taken into account only in the dominant flow direction which is radial in this case. In other directions default values are set to large numbers (in Fluent) so that the velocities are very small in the angular and transverse directions.

Airflow properties in all regions in the heating zone are assumed uniform and taken at specified temperature. Considering the low air flow velocities associated with low Reynolds numbers enables the physical modelling approach as to be as laminar flow, unsteady combined with heat transfer. A structured computational mesh is used for flow and heat transfer calculations in the $5^{\circ}$ sector. A node number of 8241 was sufficient to reach a grid independent convergence of the system. The finite volume method has been employed for the calculations. Figure 4 shows the sketch of the $2 \mathrm{D}$ 
sector used for modelling. To provide the required boundary conditions, a complementary experimental programme has been undertaken and the experimental boundary conditions are used in formulating the problem. The CFD model uses the commercial code FLUENT and necessary property modifications and models constructions have been implemented via user defined routines.

\subsection{Boundary Conditions and the Solution Method}

The inlet boundary conditions are required for the air entering the domain. The air temperature and the pressure inside the system were measured using thermocouples and pitot-static tubes located inside the machine. The radial velocity of the air flowing into the system was determined experimentally at different locations. Outflow boundary condition is used at the outlet boundary of the system, thus the velocity components are left to find their own values which will have a zero spatial derivative in a direction normal to the boundary. Since a section of the system is considered, periodic boundary conditions are imposed. The flow at a periodic boundary is treated as though the opposing periodic plane is a direct neighbour to the cells adjacent to the first periodic boundary. Thus, when calculating the flow through the periodic boundary adjacent to a fluid cell, the flow conditions at the fluid cell adjacent to the opposite periodic plane are used. The calculation considered here is transient calculation as the material is subjected to transient heating as it moves along the drum. Initial conditions for the $5^{\circ}$ sector are taken as the experimental conditions at the point of non-woven feed into the machine (see Fig. 1) and transient calculations are performed using a time step of $0.001 \mathrm{~s}$. The main flow is in the radial direction from out side to inside of the drum. The radial heat transfer dominates the process. It is also assumed that within the time step of $0.001 \mathrm{~s}$, the variation in temperature in the angular direction is negligible for a $5^{\circ}$ sector of the geometry and dominated by the initial conditions. Each calculation was conducted for 22450 time steps which is equivalent to 22.45 seconds for the heating zone. This is the time the nonwoven is subjected to air flow with a belt through put speed of $5 \mathrm{~m} / \mathrm{min}$. The assessment of the numerical accuracy is done investigating the grid resolution and criteria for iterative calculations. Furthermore, the solution is validated using experimental measurements. As the fluid is considered to be as incompressible, a segregated solver, solving the governing equations sequentially has been used. The velocity pressure coupling is done using SIMPLE (Semi-Implicit Pressure Linked Equations) algorithm. It relies on 
that the momentum equation is discretised in its vector components and a modified version of the continuity equation is used to calculate the corrected pressure value.

\section{EXPERIMENTAL MEASUREMENTS}

An experimental programme was undertaken in this study to obtain data on operating conditions and to measure temperature time history of a web which undergoes a bonding process in a typical thermal bonding pilot machine. Furthermore, air permeability and thermal conductivity of the porous media were also measured.

\subsection{Air Velocity}

For the modelling of the thermal bonding process, it is essential to know the air flow distribution through the thermal bonding machine, in order to make reasonable assumptions and perform the numerical calculations with minimum computational effort. To determine the airflow velocity in the radial direction through the system, a direction independent rotating-vane anemometer (Airflow Developments Limited ${ }^{\circledR}$, UK) was used at a number of angular locations. The device has a diameter of $100 \mathrm{~mm}$, resolution of $0.01 \mathrm{~m} / \mathrm{s}$ and an accuracy of $\pm 0.15 \mathrm{~m} / \mathrm{s}$ in a range of $0.2-30 \mathrm{~m} / \mathrm{s}$ air velocity. The values were measured over time using a time averaging method, with a sampling rate of one second. Measurements for the heating zone are carried out at five cross sectional locations in the axial directions of the drum from 1-5 as shown in Fig. 5(a). The heating zone of the machine cross-section is divided into ten segments from A to $\mathrm{J}$ as shown in Figure 5(b). The angular positions specified in Figure 5(b) correspond to the points where the air velocity measurements were performed on the machine. Locations $\mathrm{L}$ and $\mathrm{M}$, the two air velocity measurement positions in the cooling zone are also shown in Figure 5(b).

Figure 6 illustrates typical air velocity measurements of the bonding system in the radial and axial directions. Measurements were obtained at all cross-sections (1-5) and radial directions (A-J). A sample of results is shown in Figure 6(a) and (b), corresponding to the measurement location $\mathrm{B}$ and 4 respectively.

The radial air velocity measurements show large variations in a given cross-section as well as in the longitudinal direction, as exemplified in Figures 6(a) and 6(b) 
respectively. These variations are attributed to the design and construction of the machine that feeds the air into the enclosed chamber in a non-uniform manner. It was decided to use the average of the air velocities measured from $A$ to $J$ in the numerical modelling since the net effect of subjecting the nonwoven to the average air flow during the heating period or to the air flow with the measured profile would have approximately the same effect on heating the nonwoven web. This would also simplify the modelling effort.

\subsection{Air Permeability}

In the modelling of the thermal fusion bonding process the porosity and the related permeability of the web and the machine layers play a significant role, hence they need to be accurately determined and modelled. The air permeability tests of the nonwoven samples, as well as the conveyor belt and drum cover were performed using the air permeability test device (model 21443, Karl Frank GmbH, FRG). The porous nonwoven samples required conditioning prior to the tests, in the standard atmosphere for testing textiles according to BS20139, i.e., a relative humidity of $65 \%$ $\pm 2 \%$ and a temperature of $20^{\circ} \mathrm{C} \pm 2^{\circ} \mathrm{C}$ for $24 \mathrm{~h}$. The tested surface area of the specimens was $20 \mathrm{~cm}^{2}$. Measurements were carried out using specimens taken from different locations of a particular nonwoven sample. The error of the technique is \pm 1 $1 / \mathrm{m}^{2} \mathrm{~s}$. The air permeability of the drum was calculated from the dimensions of the uniformly distributed holes (perforations) in the drum.

Figure 7 shows the results of the pressure drop versus air velocity for the thermally bonded nonwoven web of $200 \mathrm{~g} / \mathrm{m}^{2}$. Similar nonlinear curves with different gradients were obtained for different nonwoven webs within a fabric density range of $100 \mathrm{~g} / \mathrm{m}^{2}$ $250 \mathrm{~g} / \mathrm{m}^{2}$. A decrease in air permeability was observed, as expected, with an increase in the fabric weight, all demonstrating similar non-linear relationships. The pressure drop was used to determine the air permeability.

The non linear relationship between the velocity and the pressure drop indicate that the data does not comply with Darcy's law. The reason for the departing behaviour from linearity is the energy loss due to the inertial resistance of the air flow in addition to its viscous dissipation. Using the non-linear relationship obtained from 
experiments, the coefficients $a$ and $b$ in equation (6) are obtained to be used in the CFD model.

Figure 8(a) and 8(b) show the pressure drop against the air velocity for the belt and drum cover respectively. The results reveal that both structures show nonlinear flow behaviour too. This suggests that the modelling process for the nonwoven web, belt and drum cover should include the inertial resistance.

\subsection{Thermal Conductivity}

The effective thermal conductivity of the porous fibrous structure is determined by the properties of the constituent fibres and interspaced voids filled by air, which was measured experimentally, using the heat conduction unit (H940, P. A. Hilton Ltd. ${ }^{\circledR}$, UK). The equipment comprises a multi section bar for the measurement of linear conduction. The section is equipped with an array of temperature sensors. Cooling water was supplied at 2 litres/min rate to one side of the test device to maintain a steady gradient. The thermal conductivity measurement for the $200 \mathrm{~g} / \mathrm{m}^{2}$ nonwoven resulted in a value of $0.17 \mathrm{~W} / \mathrm{m}^{\circ} \mathrm{C}$. Thermal conductivity of the belt and drum cover are calculated from the analytical equation (16).

\subsection{Web Surface Temperature}

The temperature profile of the porous fibrous web as it progresses through the thermal fusion bonding process is an important parameter. The temperatures of both surfaces of the fibrous web as well as the mid point through its thickness were measured using thermocouples (Newport Omega $\left.{ }^{\circledR}, \mathrm{UK}\right)$. The results of the measurements are used for the validation of the computational fluid dynamics model. A 200gsm nonwoven consisting of two layers of $100 \mathrm{gsm}$ web was used to measure temperature distribution. The thermocouples were attached to each surface of the nonwoven as well as between the two layers. The thermocouples were allowed to travel through the machine together with the nonwoven web hence measuring the temperature profile with respect to time. Hence, for a given web throughput velocity the temperature profile with respect to the angular position can be determined.

\section{CFD RESULTS AND EXPERIMENTAL VALIDATION}


The proposed 2D macro model is validated using the experimentally determined web temperature profile. CFD analyses were performed for air temperatures of $225^{\circ} \mathrm{C}$, $230^{\circ} \mathrm{C}$ and $235^{\circ} \mathrm{C}$. The web is made of sheath-core type bi-component fibres of nylon (PA6) sheath and polyester (PET) core with a nonwoven thickness of $0.909 \mathrm{~mm}$ corresponding to $200 \mathrm{~g} / \mathrm{m}^{2}$ fabric weight. The web throughput speed was $5 \mathrm{~m} / \mathrm{min}$. The belt is of continuous loop and travels outside the machine before it enters the machine again. Hence its temperature drops almost to room temperature. The initial temperatures of the belt and nonwoven web were therefore taken as $30^{\circ} \mathrm{C}$ and $23^{\circ} \mathrm{C}$ respectively based on experimental measurements. The temperature of both the drum and the drum cover drops much below the heated air inlet temperature due to heat loss of the air to the belt and nonwoven web before it reaches the drum cover and the drum. Furthermore, all layers are subjected to a cold air blast in zones L and $\mathrm{M}$ immediately after the heating zone, which further reduces the temperature of the drum and the drum cover. Both the drum cover and the drum are also briefly exposed as shown in Figure 1, where the temperature was measured and taken as $145^{\circ} \mathrm{C}$ in the CFD model. A uniform air velocity of $0.66 \mathrm{~m} / \mathrm{s}$, which was determined from the experimental measurements of the air flow inside the machine, is used for the numerical computations.

Figure 9 illustrates the numerically computed temperature distribution of the nonwoven fabric over time for three different air temperatures together with the experimentally measured values. The graphs show that the temperature of the nonwoven rises nonlinearly with an initial steep gradient. This is due to instant contact of the nonwoven web with the drum cover at $145^{\circ} \mathrm{C}$ and the hot air flowing through it, initially at $225^{\circ} \mathrm{C}-235^{\circ} \mathrm{C}$. As the nonwoven's temperature approaches the air temperature, the curves level out. It can be seen that CFD model results and the experimental measurements agree very well for all three air inlet temperatures considered.

Figure 10 shows that the temperature distributions of the centre and the top and bottom surface of the nonwoven web agree very well with the CFD simulation results. A considerable temperature difference between the drum cover side and the belt side of the nonwoven fabric was recorded. The higher temperature rise on the face of the fabric on the drum cover side in comparison to the belt side is due to the contact with 
hot surface of the drum cover $\left(145^{\circ} \mathrm{C}\right)$ on this side and cooler surface contact on the belt side $\left(30^{\circ} \mathrm{C}\right)$. In practice the consequences of this temperature difference manifests itself on the surface texture. The model appears to be effective in predicting trends as well as actual values observed in the experiments.

Figure 11 shows the predicted temperature distribution of all the four system components as a function of time at an air inlet temperature of $225^{\circ} \mathrm{C}$. The computed temperature distributions show that the nonwoven and the belt, initially at similar ambient temperatures, follow a similar heating curve. The belt and the nonwoven temperature rise at a rate proportional to the difference in temperature from the hot air. The behaviour of the drum and drum cover show a typical cooling process within the first 2.5 seconds of the process (approximately $10 \%$ of the dwell time) due to their contact with the cooler surface of the nonwoven web which is adjacent to the belt at a similar temperature. Because the drum cover is at an initial temperature of $145^{\circ} \mathrm{C}$, as it makes direct contact with the web at room temperature, the heat initially flows from the drum cover towards the web at a fast rate, due to high temperature gradient, increasing the temperature of the web and reducing that of the drum cover. The temperature of the drum, located behind the drum cover, initially drops at a slower rate than the drum cover since it is not in direct contact with the web. The drum loses heat to the faster cooling drum cover. At approximately 2.5 seconds the temperature of all four layers reaches equilibrium. From this point on, the heating is solely governed by the hot air flowing through the components, causing an increase in their temperature of all layers. The belt and the nonwoven follow a similar heating curve with a steeper gradient than that of the drum and drum cover.

The temperature values show that the belt reaches the highest temperature value which is at the interface with the hot air, the drum having the lowest temperature rise being the last layer in the direction of the air flow. The temperature of the nonwoven eventually reaches the melting point of the sheath material of the bi-component fibre.

\section{CONCLUSIONS}

A computational model of the thermal fusion process of a nonwoven web is developed and experimentally validated. The machine configuration and the 
properties of all three layers comprising the belt, drum cover and drum, as well as the nonwoven web, were represented sufficiently accurately in the model to produce good agreement with experiment. The properties of the materials, such as thermal conductivity, permeability and porosity were determined using experiments and calculations. The model was validated by using the experimentally determined temperature profile of the nonwoven web during the process. It was shown that the heating of the nonwoven web at $23^{\circ} \mathrm{C}$ for the first 2.5 seconds is primarily due to the conductive process due to the contact with the adjacent drum cover and its neighbouring drum at a high initial temperature of $145^{\circ} \mathrm{C}$. Then the hot air flow becomes the only factor in heating all four layers of the system. The temperature of the nonwoven web reaches the melting point of the sheath component of the bicomponent fibres, enabling the thermal fusion of the fibres in contact with each other to produce a bonded web.

The model shows how the temperature of different layers, namely the belt, nonwoven, drum cover and drum vary throughout the process in each cycle. The computational model could be used as an economical tool to design and optimise processes for product development reducing the cost product trials. It can also be used for optimising the machine components.

\section{ACKNOWLEDGEMENT}

We gratefully acknowledge the financial and technical support provided by COLBOND bv, The Netherlands, for this research.

\section{REFERENCES}

1 Butler, I. The Nonwoven Fabrics Handbook, 1999, (Cary, NC: Association of the Nonwoven Fabrics Industry-INDA).

2 Hossain, M., Acar, M. and Malalasekera, W., A Mathematical Model for transverse Airflow and Heat Transfer Through Fibrous Webs, Proceedings of the Institution of Mechanical Engineers Part E: Journal of Process Mechanical Engineering, 2005, Vol. 219, pp. 357-366.

3 Forchheimer, P. Wasserbewegung durch Boden. Z. Ver. Deutsch. Ing., 1901, 45, p. 1782. 
4 Ergun, S. Fluid flow through packed columns. Chemical Engineering Progress, 1952, Vol. 48, No. 2, pp. 89-94.

5 De Boer, R. Theory of Porous Media: Highlights in the historical development and current state. Springer-Verlag, 2000, Berlin, Heidelberg, New York.

6 Luo, S. Y. and Mitra, A. Finite elastic behavior of flexible fabric composite under biaxial loading. J. Appl. Mech., 1999, Vol. 66, pp. 631-638.

$7 \mathbf{X u}$, J. and Wirtz, R. A. In-Plane effective thermal conductivity of plain-weave screen laminates. IEEE Transactions on components and packaging technologies, 2002, Vol. 25, No.4, pp. 615-619.

$8 \mathbf{X u}$, J. and Wirtz, R. A. In-Plane Effective Thermal Conductivity of Symmetric, Diamond-Weave Screen Laminates. Journal of Electronic Packaging, 2005, Vol. 127, pp. 353-356.

9 McGregor, R. The Effect of Rate of Flow on Rate of Dyeing. Part II - The Mechanism of Fluid Flow through Textiles and its Significance in Dyeing. Journal of the Society of Dyers and Colourists, 1965, Vol. 81, pp. 429-438. 


\section{LIST OF FIGURES}

Figure 1: Schematic illustration of (a) a typical through-air bonding system and (b) close up of machine layers including the nonwoven web.

Figure 2: Physical modelling of wire mesh structures: (a) discrete model; (b) unit cell; (c) mesh thickness.

Figure 3: SEM image of thermally bonded $200 \mathrm{gr} / \mathrm{m}^{2}$ web morphology.

Figure 4: Boundary conditions of the CFD model.

Figure 5: Velocity measurement positions: (a) cross sections along the length and (b) radial positions in a given cross section of the drum.

Figure 6: Experimentally determined air velocity distribution: (a) in radial direction and (b) in axial direction.

Figure 7: Experimentally determined pressure drop vs. air velocity of $200 \mathrm{~g} / \mathrm{m}^{2}$ web.

Figure 8: Air permeability measurements: (a) conveyer belt; (b) drum cover.

Figure 9: Temperature distribution of nonwoven fabric and experimental validation: (a) $225^{\circ} \mathrm{C}$; (b) $230^{\circ} \mathrm{C}$; and (c) $235^{\circ} \mathrm{C}$.

Figure 10: Calculated and measured temperature distributions of top surface, middle and bottom surface of the nonwoven web.

Figure 11: Numerically predicted temperature distribution of the four layers of the through-air bonding system at $225^{\circ} \mathrm{C}$. 


\section{LIST OF FIGURES}

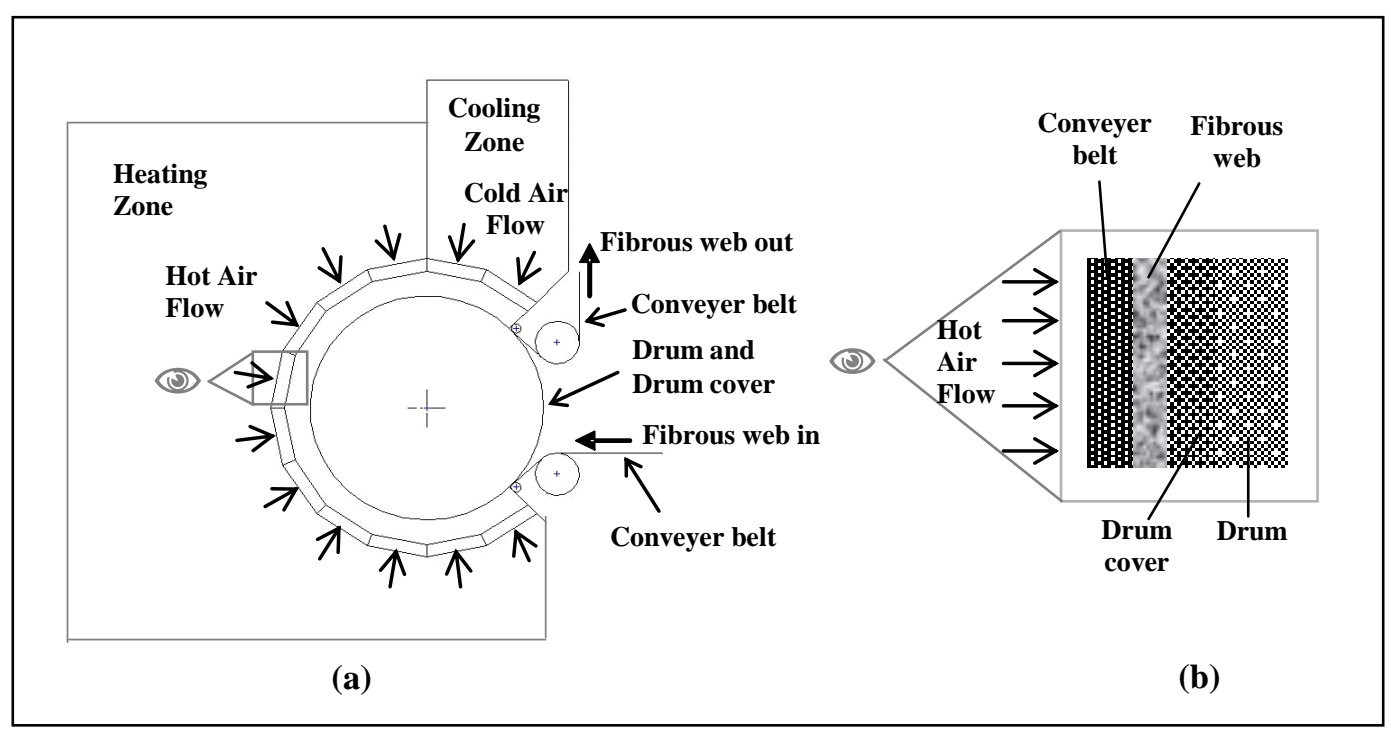

Peksen, Acar, Malalasekera

Figure 1 


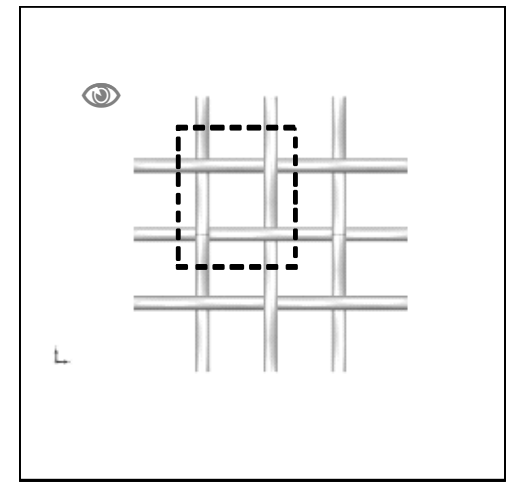

(a)

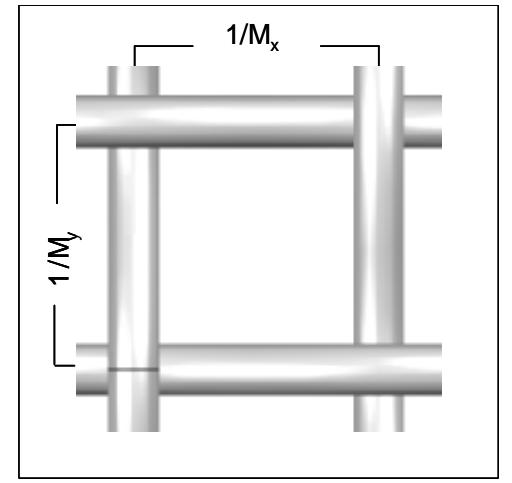

(b)

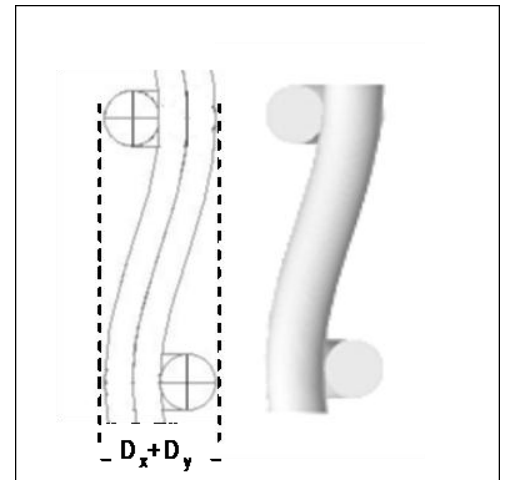

(c)

Peksen, Acar, Malalasekera

Figure 2 


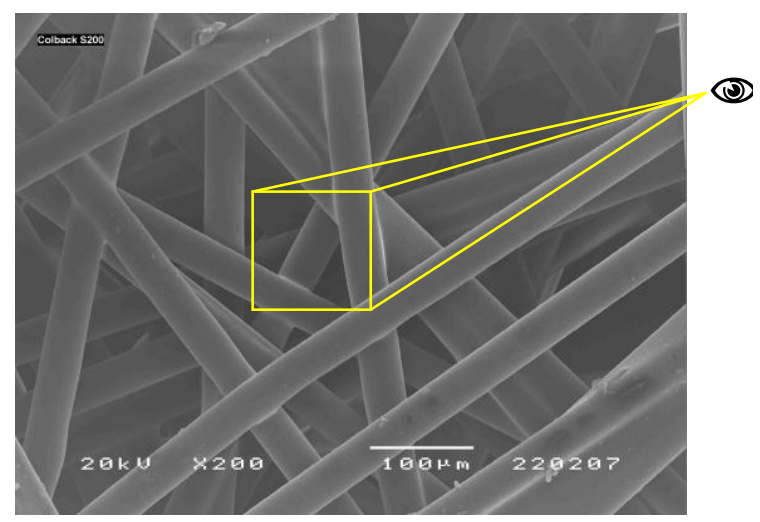

Peksen, Acar, Malalasekera

Figure 3 


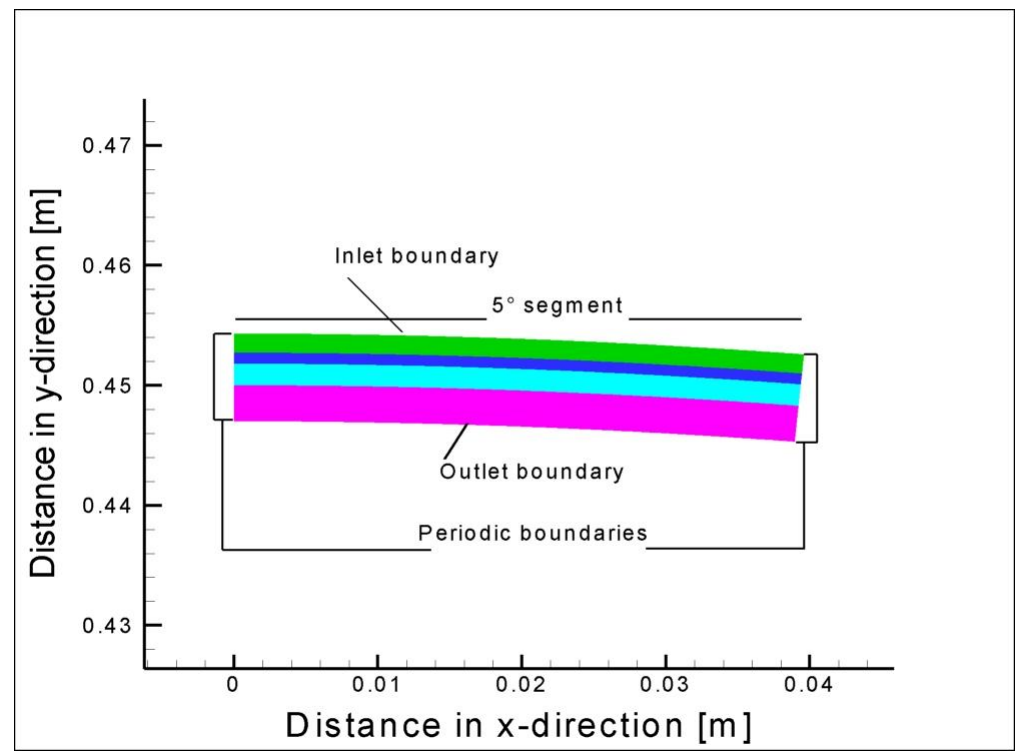

Peksen, Acar, Malalasekera

Figure 4 


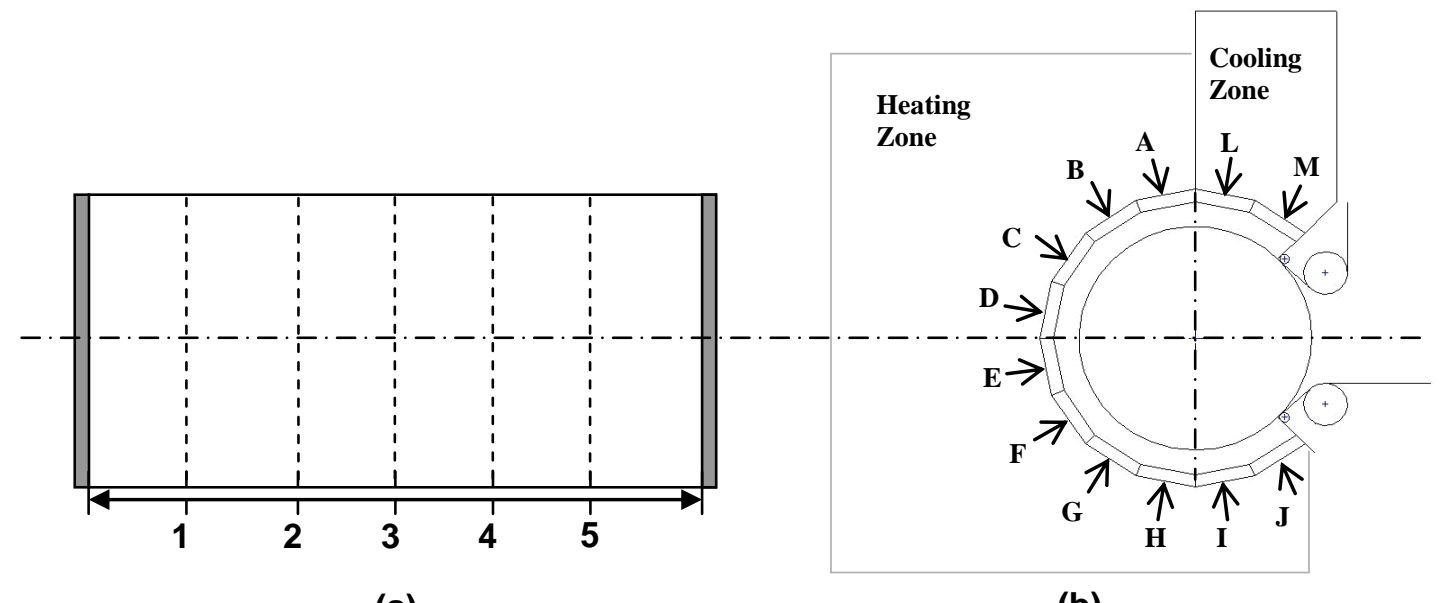

(a)

(b)

Peksen, Acar, Malalasekera

Figure 5 


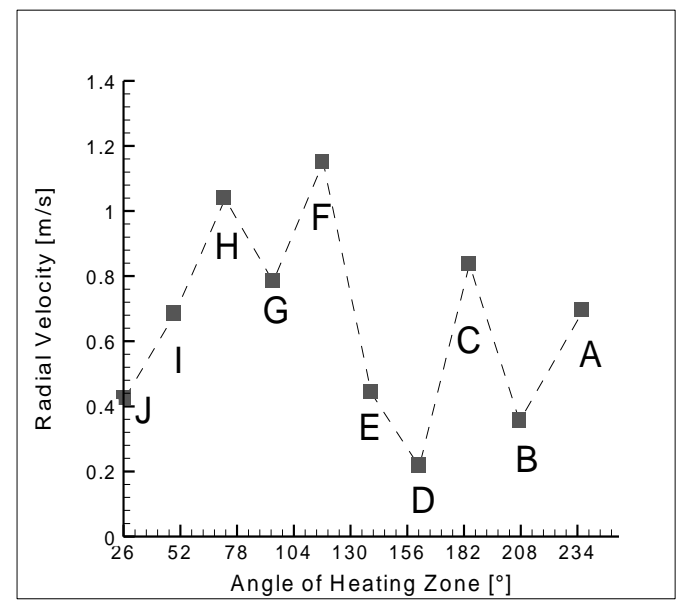

a)

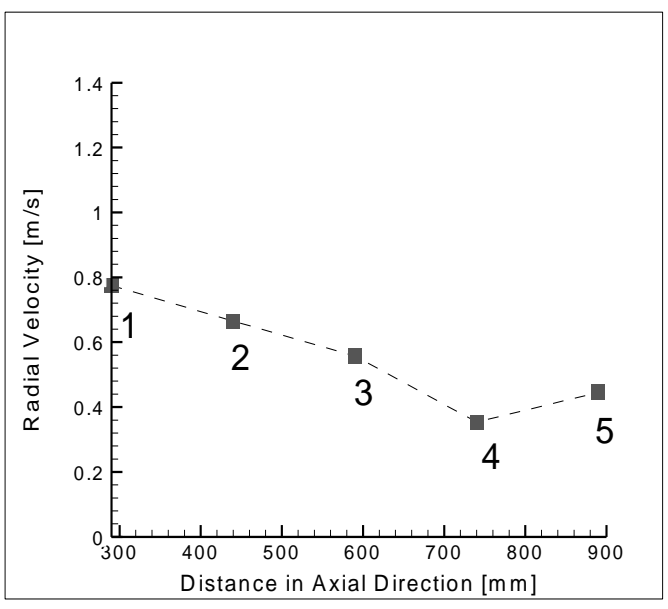

b)

Peksen, Acar, Malalasekera

Figure 6 


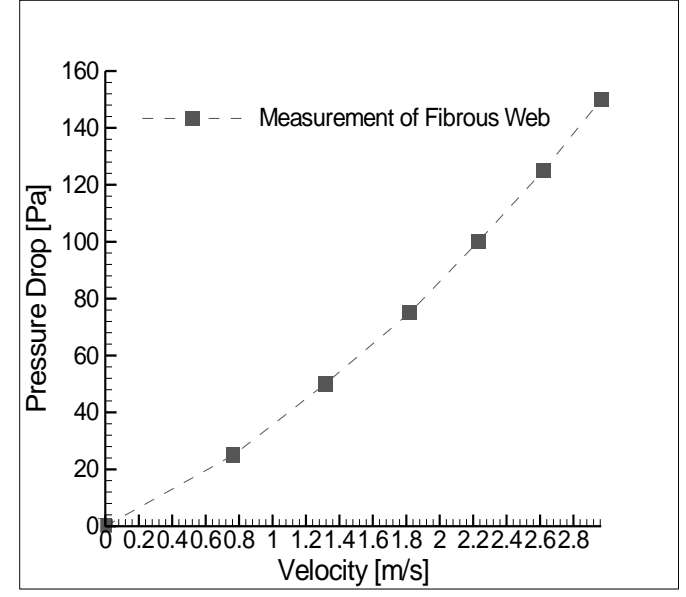

Peksen, Acar, Malalasekera

Figure 7 


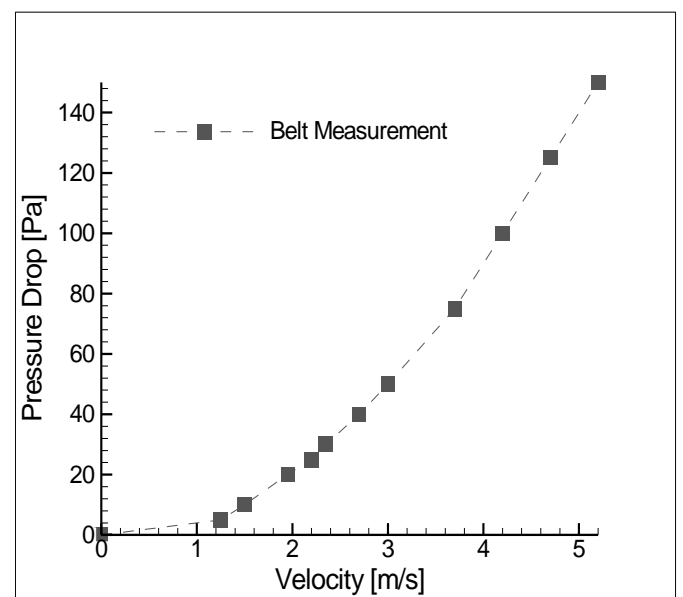

a)

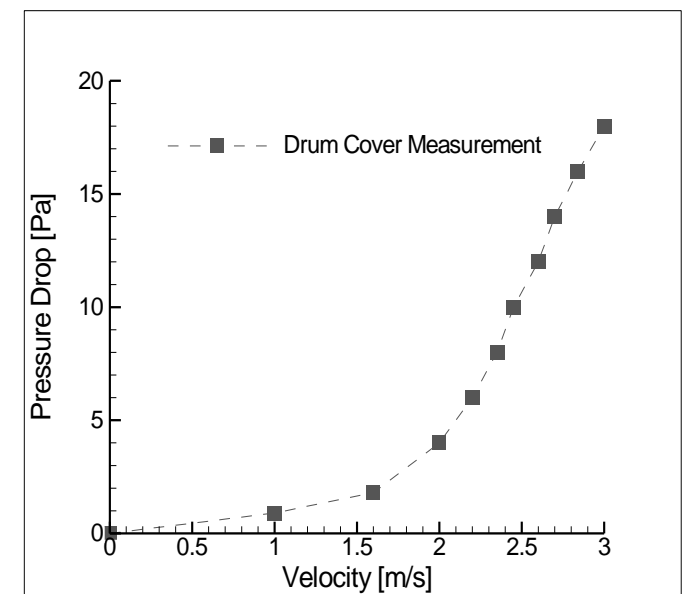

b)

Peksen, Acar, Malalasekera

Figure 8 


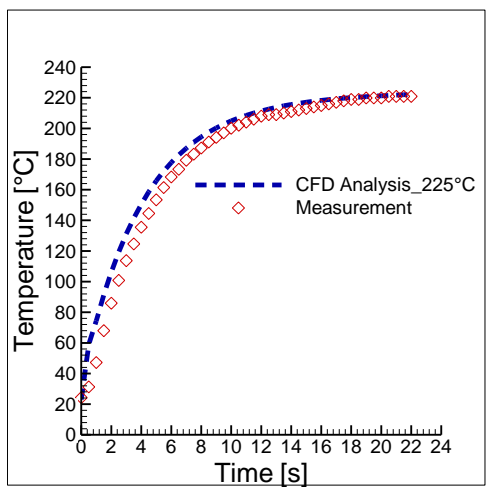

(a)

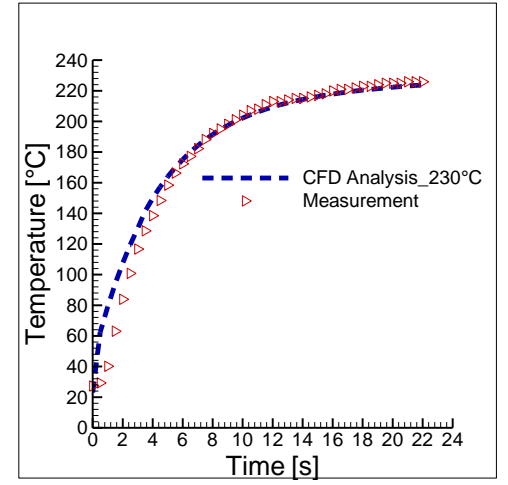

(b)

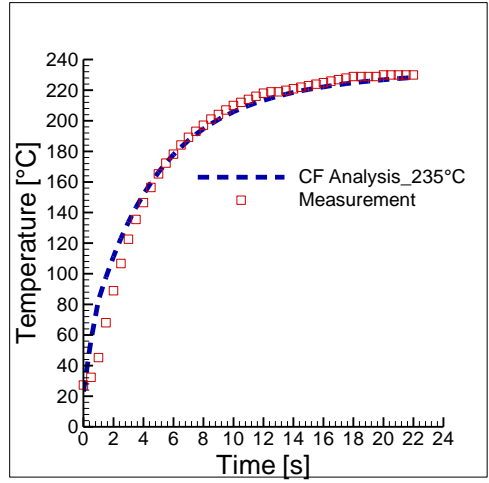

(c)

Peksen, Acar, Malalasekera

Figure 9 


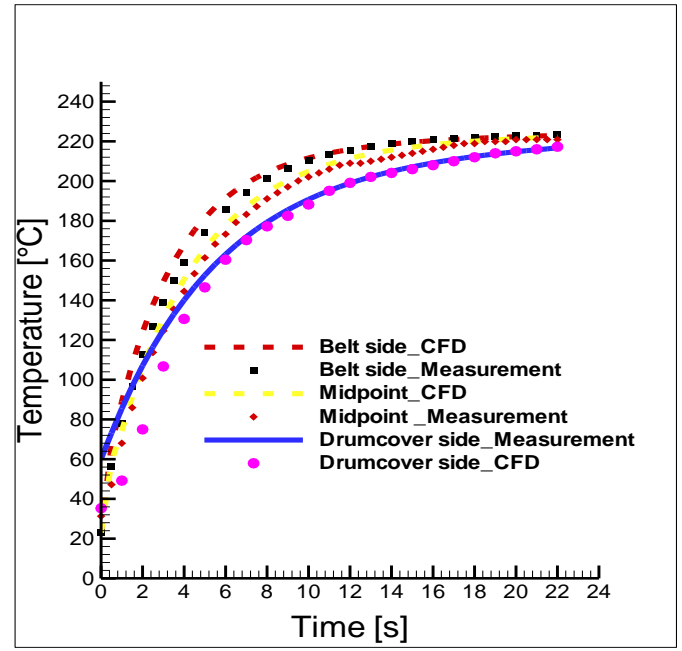

Peksen, Acar, Malalasekera

Figure 10 


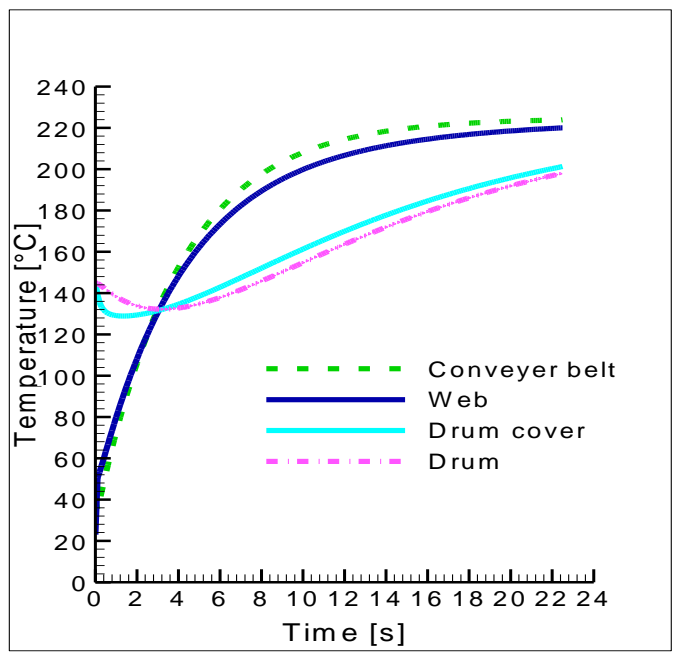

Peksen, Acar, Malalasekera

Figure 11 